\title{
IRF5 is associated with adverse postoperative prognosis of patients with non-metastatic clear cell renal cell carcinoma
}

\author{
Qi Bai ${ }^{1, *}$, Li Liu, ${ }^{1, *}$, Yu Xia ${ }^{1, *}$, Jiajun Wang ${ }^{1}$, Wei Xi ${ }^{1}$, Yang Qu ${ }^{1}$, Ying Xiong ${ }^{1}$, Qilai \\ Long $^{1}$, Jiejie $X^{2}{ }^{2}$ and Jianming Guo ${ }^{1}$ \\ ${ }^{1}$ Department of Urology, Zhongshan Hospital, Fudan University, Shanghai 200032, China \\ ${ }^{2}$ Department of Biochemistry and Molecular Biology, School of Basic Medical Sciences, Fudan University, Shanghai 200032, \\ China \\ *These authors contributed equally to this work \\ Correspondence to: Jiejie Xu, email: jjxufdu@fudan.edu.cn \\ Jianming Guo, email: guo.jianming@zs-hospital.sh.cn
}

Keywords: clear cell renal cell carcinoma, IFN regulatory factor-5, nomogram, overall survival, recurrence free survival

Received: November 24, 2016

Accepted: April 25, 2017

Published: May 11, 2017

Copyright: Bai et al. This is an open-access article distributed under the terms of the Creative Commons Attribution License 3.0 (CC BY 3.0 ), which permits unrestricted use, distribution, and reproduction in any medium, provided the original author and source are credited.

\section{ABSTRACT}

Background: IRF5 is one member of IRFs family, and is critical for host immunity and cell response. In the present study, we sought to search the clinical and prognostic value of IFR5 in patients with non-metastatic CCRCC.

Results: IRF5 proved to be an adverse independent prognostic factor for overall survival $(p<0.001)$ and recurrence free survival $(p=0.002)$. The newly built nomograms could give better prediction for overall survival and recurrence free survival in cCRCC patients.

Materials and Methods: We included 264 individuals who were diagnosed with nonmetastatic clear cell renal cell carcinoma in the present study. Immunohistochemistry staining was performed on tissue microarrays to evaluate the IRF5 expression. $X^{2}$ test, Fisher's exact test, $\boldsymbol{t}$ test, Kaplan-Meier method and Cox proportional hazard model were applied to evaluate the prognostic value of IRF5. Two nomograms were constructed to predict clinical outcomes for cCRCC patients after surgery.

Conclusions: IRF5 was an adverse independent prognostic factor for both overall survival and recurrence free survival in patients with non-metastatic ccRCC.

\section{INTRODUCTION}

Renal cell carcinoma (RCC) represents $3 \%$ of all malignant tumors in adults [1]. The majority of RCC $(70 \%)$ are classified as clear cell renal cell carcinoma (ccRCC) [2]. Despite most newly diagnosed RCC cases are early-stage and organ confined, approximately $25-30 \%$ of patients with RCC are presented with metastatic RCC (mRCC) at the time of diagnosis $[3,4]$. Meantime $30 \%$ of the patients with localized disease will ultimately develop metastases even after the curative surgeries [5]. The nature history of $\mathrm{mRCC}$ is highly variable, with median overall survival of only 2 years [6-8]. We believe that continuous exploration of RCC biology and novel approaches to RCC management could help physicians in the process of surgical intervention and postsurgical medical intervention.

Clear cell renal cell carcinoma is a kind of heterogeneous disease. Multiple mediators, which were produced by the tumor itself or stromal compartments within the tumor microenvironment (TME) have profoundly influence on tumor behaviors. These mediators could serve as makers of tumor stage or novel targets for tumor treatment. Interferon regulatory factory 5 (IRF5) is a transcription factor that is responsible for type I IFN signaling [9] and multiple immune activities [10-12]. Increasing studies indicate that IRF5 could participate in the cellular response to stressors, including virus, DNA damage, and death receptor signaling [9, 13-15]. IRF5 could also regulate induction of multiple pro-inflammatory cytokines $[16,17]$, and then shaped the 
network of tumor immune microenvironment. Recently, the role of IRF5 in malignancy remains largely unknown and kind of controversial. Thus, better understanding of IRF5 may contribute an additional therapy target to the disease management and requires further attention.

The focus of the present study was to examine the clinical and prognostic importance of IRF5 in ccRCC. We had analyzed the expression of IRF5 by immunohistochemistry in ccRCC tissues and built two prediction models for overall survival (OS) and recurrence free survival (RFS), which integrated with other prognostic parameters, to refine individual risk stratification in nonmetastatic ccRCC patients.

\section{RESULTS}

\section{IRF5 expression and its association with pathological characteristics}

IRF5 positive staining in ccRCC predominantly located in the nuclear and cytoplasm (Figure 1). According to IRF5 expression, $30.3 \%(80 / 264)$ of patients were defined as high IRF5 expression. Table 1 showes detail characteristic of the study population and its correlation with IRF5. The median follow-up time was 99.7 (rang: 3-120) months. IRF5 expression was not associated with age, gender ECOG PS, T stage, Fuhrman grade or necrosis.

\section{Kaplan-Meier survival analysis and subgroup analysis}

The Kaplan-Meier survival method was applied to analyze OS and RFS according to IRF5 expression. Patients with high IRF5 expression had significantly poorer OS $(p=0.001)$ and RFS $(p=0.002)$ (Figure 2A, 2B) than those with low IRF5 expression. In the further study, we analyzed IRF5 expression in different $\mathrm{T}$ stage and Fuhrman grade subgroups. We found that the unfavorable prognostic value of IRF5 in lower risk ccRCC patients. For the OS, the low/ high expression of IFR5 could only distinguish patients with dismal outcome in T stage $(1+2)$ group (Figure $3 \mathrm{~A}, p=0.001$ ) and Fuhrman grade $(\mathrm{I}+\mathrm{II})$ group (Figure $3 \mathrm{C}, p=0.002$ ) but not in $\mathrm{T}$ stage $(3+4)$ group (Figure $3 \mathrm{~B}, p=0.217$ ) or Fuhrman grade (III+IV) group (Figure $3 \mathrm{D}, p=0.140$ ). And for RFS, the prognostic value of IRF5 is significant in patients in both T stage $(1+2$ and $3+4)$ groups (Figure $3 \mathrm{E}, 3 \mathrm{~F}$, $p=0.020$ and $p=0.035$ respectively) and Fuhrman grade (I+II) group (Figure $3 \mathrm{G}, p=0.005$ ) but not in Fuhrman grade (III+IV) group (Figure $3 \mathrm{H}, p=0.167$ ).

\section{Cox regression analyses}

To investigate if IRF5 was an independent prognostic factor for OS and RFS, univariate and multivariate Cox regression models were used. We analyzed T stage, Fuhrman grade, necrosis and ECOG PS in univariate analysis. The variables have long been used as predictors for patients with ccRCC. After univariate analysis, we included the statistically significant parameters into multivariate analysis (Table 2). The hazard ratio of IRF5 expression was 2.21 (95\% CI: 1.38-3.55, $p<0.001)$ and 2.10 (95\% CI: $1.30-3.37, p=0.002)$ for OS and RFS respectively. The results showed that IRF5 could serve as an adverse independent prognostic factor for both OS and RFS.

\section{Nomogram for predicting OS and RFS in ccRCC}

On the basis of results above, we attempted to build a prediction model that incorporating of IRF5 expression and other prognostic parameters to give a better stratification of clinical outcomes. The prognostic parameters include T stage, Fuhrman grade and presence of necrosis. We constructed two nomograms to predict

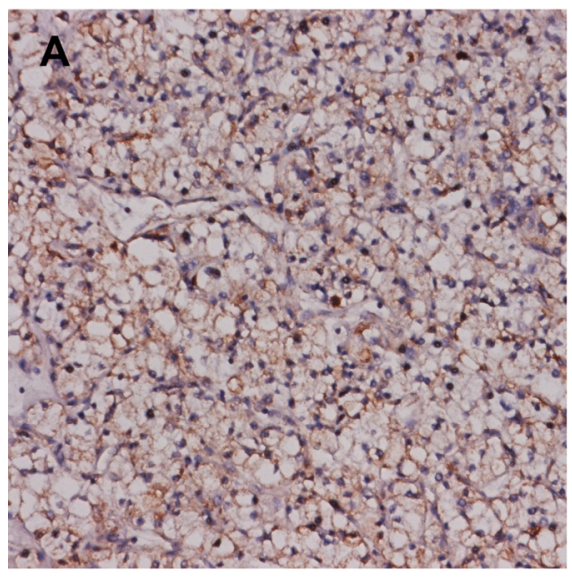

IRF5 high expression

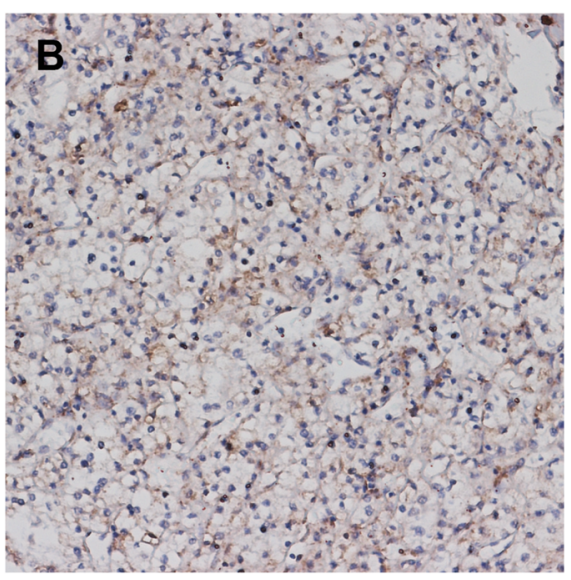

IRF5 low expression

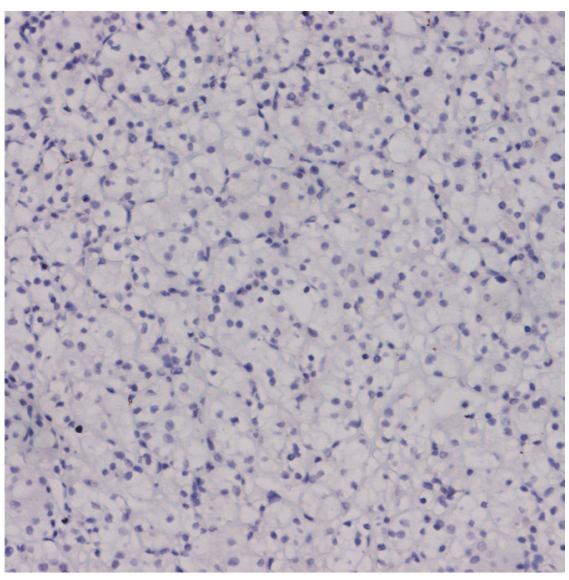

IRF5 negative

Figure 1: Representative pictures of IRF5 immunostaining. High IRF5 expression in tumor tissue (A) low IRF5 expression in tumor tissue $(\mathbf{B})$ negative IRF5 expression in tumor tissue. Original magnification: $\times 200$. 
Table 1: Correlation between IRF5 expression and clinical characteristics in localized ccRCC patients

\begin{tabular}{|c|c|c|c|c|c|}
\hline \multirow{2}{*}{ Variables } & \multicolumn{2}{|l|}{ All patients } & \multicolumn{3}{|c|}{ IRF5 expression } \\
\hline & No. & $\%$ & Low & High & $p^{*}$ \\
\hline Age at surgery. yr & & & & & 0.874 \\
\hline Mean \pm SD & $55.1 \pm 12.9$ & & $55.2 \pm 13.2$ & $54.9 \pm 12.4$ & \\
\hline Gender & & & & & 0.895 \\
\hline Female & 81 & 30.7 & 56 & 25 & \\
\hline Male & 183 & 69.3 & 128 & 55 & \\
\hline ECOG PS & & & & & 0.470 \\
\hline 0 & 190 & 72.0 & 130 & 60 & \\
\hline$\geq 1$ & 74 & 28.0 & 54 & 20 & \\
\hline Surgery & & & & & 0.362 \\
\hline Partial nephrectomy & 19 & 7.2 & 15 & 4 & \\
\hline Radical nephrectomy & 245 & 92.8 & 169 & 76 & \\
\hline Pathological T stage & & & & & 0.730 \\
\hline pT1 & 185 & 70.0 & 130 & 55 & \\
\hline pT2 & 19 & 7.2 & 12 & 7 & \\
\hline pT3 & 58 & 22.0 & 40 & 18 & \\
\hline pT4 & 2 & 0.8 & 2 & 0 & \\
\hline Fuhrman nuclear grade & & & & & 0.830 \\
\hline 1 & 29 & 11.0 & 19 & 10 & \\
\hline 2 & 204 & 77.3 & 144 & 60 & \\
\hline 3 & 31 & 11.7 & 21 & 10 & \\
\hline Necrosis & & & & & 0.686 \\
\hline Absent & 231 & 87.5 & 162 & 69 & \\
\hline Present & 33 & 12.5 & 22 & 11 & \\
\hline
\end{tabular}

Abbreviations: ccRCC: clear cell renal cell carcinoma. ECOG PS: Eastern Cooperative Oncology Group performance status. SD: standard deviation.

$* t$ test, $\chi^{2}$ test or Fisher's exact test were performed. $p<0.05$ was regard as statistically significant.

$\mathrm{OS}$ and RFS at 5 and 8 years after surgery (Figure 4A, 4B). Higher total point indicated worse outcome. The calibration plots of the nomograms were shown for OS (Figure 4C, 4D) and RFS (Figure 4E, 4F). The Harrell's c-indices for OS and RFS were 0.78 (95\% CI, 0.72-0.83) and $0.77(95 \% \mathrm{CI}, 0.71-0.83)$ respectively, higher than the combination of other prediction factors except IRF5, 0.72 (95\% CI, 0.66-0.78) for OS and 0.70 (95\% CI: 0.64-0.76) for RFS. So we believed that the newly constructed model could give a better prediction for OS and RFS.

\section{DISCUSSION}

Currently, several clinical and/or genomic factors have been proposed to identify RCC patients who are at greater risk of disease progression [18-22]. In the present study, we examined the prognostic value of IRF5 in non-metastatic ccRCC patients. The results presented here provide for the first time that high IRF5 expression correlated with ccRCC development and progression. We also found that IRF5 could further stratify the patients in lower risk group like pT stage (1 and 2) or Fuhrman grade (1 and 2). Numerous biomarkers have been investigated, but little of them could improve the predictive accuracy of the current prognostic systems. The present nomograms which integrated IRF5 with other prognostic parameters could give a better risk stratification for OS and RFS in non-metastatic ccRCC patients.

IRFs have multiple functions and abnormal expression could lead to aberrant biological cell behaviors [23]. Currently, little is known about their roles in ccRCC development and progression. IRF5 is one member of IRFs family, and is critical for host immunity and the cellular response to extracellular stressors [10, 12]. IRF5 also plays essential roles in the cell growth, cell cycle, innate antiviral and inflammatory responses $[9,13,17,24]$. 
Table 2: Univariate and multivariate cox regression analyses for overall survival and recurrence free survival in localized ccRCC patients

\begin{tabular}{|c|c|c|c|c|}
\hline \multirow{2}{*}{ Variables } & \multicolumn{2}{|c|}{ Univariate analysis } & \multicolumn{2}{|c|}{ Multivariate analysis } \\
\hline & HR(95\% CI) & $p^{*}$ & HR(95\% CI) & $p^{*}$ \\
\hline \multicolumn{5}{|l|}{ Overall survival } \\
\hline pT stage & & $<0.001$ & & $<0.001$ \\
\hline pT2 vs pT1 & $3.34(1.59-7.00)$ & 0.001 & $3.35(1.58-7.12)$ & 0.002 \\
\hline $\mathrm{pT} 3$ vs pT1 & $3.43(2.04-5.77)$ & $<0.001$ & $3.35(1.95-5.76)$ & $<0.001$ \\
\hline pT4 vs pT1 & $141.81(26.42-761.37)$ & $<0.001$ & $292.79(51.87-1652.60)$ & $<0.001$ \\
\hline Fuhrman grade & & $<0.001$ & & 0.003 \\
\hline $2 v s 1$ & $1.86(0.67-5.16)$ & 0.419 & $1.34(0.48-3.79)$ & 0.578 \\
\hline $3 v s 1$ & $5.35(1.79-16.01)$ & 0.002 & $3.86(1.24-11.98)$ & 0.019 \\
\hline Necrosis (present $v s$ absent) & $2.82(1.61-4.89)$ & $<0.001$ & $1.75(0.94-3.25)$ & 0.075 \\
\hline ECOG PS $(\geq 1 v s 0)$ & $1.165(0.70-1.95)$ & 0.300 & - & - \\
\hline IRF5 (high vs low) & $2.21(1.38-3.55)$ & $<0.001$ & $2.56(1.51-3.99)$ & $<0.001$ \\
\hline \multicolumn{5}{|l|}{ Recurrence-free survival } \\
\hline pT stage & & $<0.001$ & & $<0.001$ \\
\hline $\mathrm{pT} 2$ vs $\mathrm{pT} 1$ & $3.34(1.60-6.99)$ & 0.001 & $3.33(1.57-7.04)$ & 0.002 \\
\hline $\mathrm{pT} 3$ vs pT1 & $3.12(1.86-5.22)$ & $<0.001$ & $3.19(1.86-5.48)$ & $<0.001$ \\
\hline $\mathrm{pT} 4$ vs pT1 & $42.18(5.22-340.41)$ & $<0.001$ & $85.04(10.14-712.85)$ & $<0.001$ \\
\hline Fuhrman grade & & $<0.001$ & & 0.006 \\
\hline $2 v s 1$ & $1.88(0.68-5.21)$ & 0.224 & $1.44(0.51-4.05)$ & 0.492 \\
\hline $3 v s 1$ & $5.34(1.78-15.99)$ & 0.003 & $3.78(1.22-11.67)$ & 0.021 \\
\hline Necrosis (present $v s$ absent) & $3.12(1.82-5.35)$ & $<0.001$ & $2.14(1.18-3.89)$ & 0.012 \\
\hline ECOG PS $(\geq 1 v s 0)$ & $1.04(0.62-1.76)$ & 0.891 & - & - \\
\hline IRF5 (high vs low) & $2.10(1.30-3.37)$ & 0.002 & $2.29(1.42-3.71)$ & 0.001 \\
\hline
\end{tabular}

Abbreviations: ECOG PS: Eastern Cooperative Oncology Group performance status; HR: hazard ratio; CI: confidence interval; ccRCC: clear cell renal cell carcinoma.

*Data obtained from the Cox proportional hazards model; $p<0.05$ was regard as statistically significant.
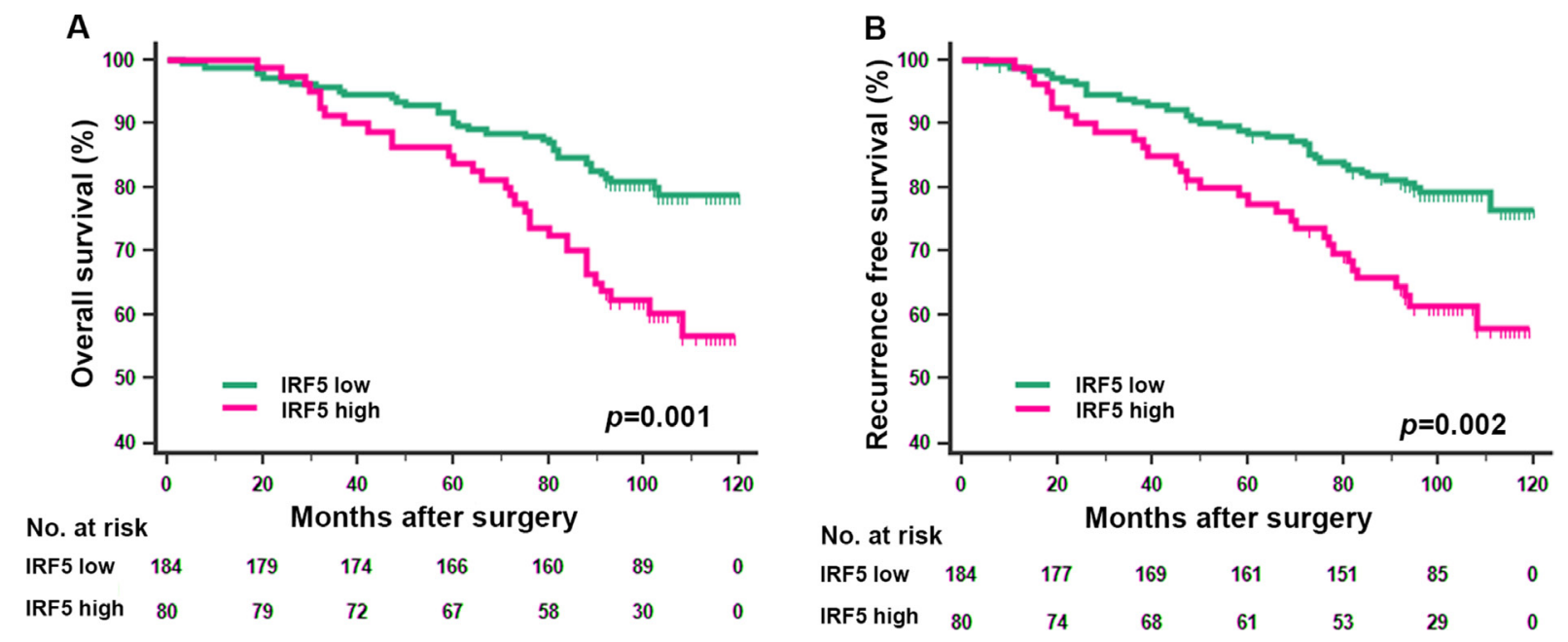

Figure 2: Kaplan-Meier analyses for overall survival and recurrence free survival of patients with ccRCC according to IRF5 expression. Overall survival according to IRF5expression in non-metastatic ccRCC (A) recurrence free survival according to IRF5expression in non-metastatic ccRCC (B) $p$-value was calculated by Log rank test, $p<0.05$ was regarded as statistically significant. 

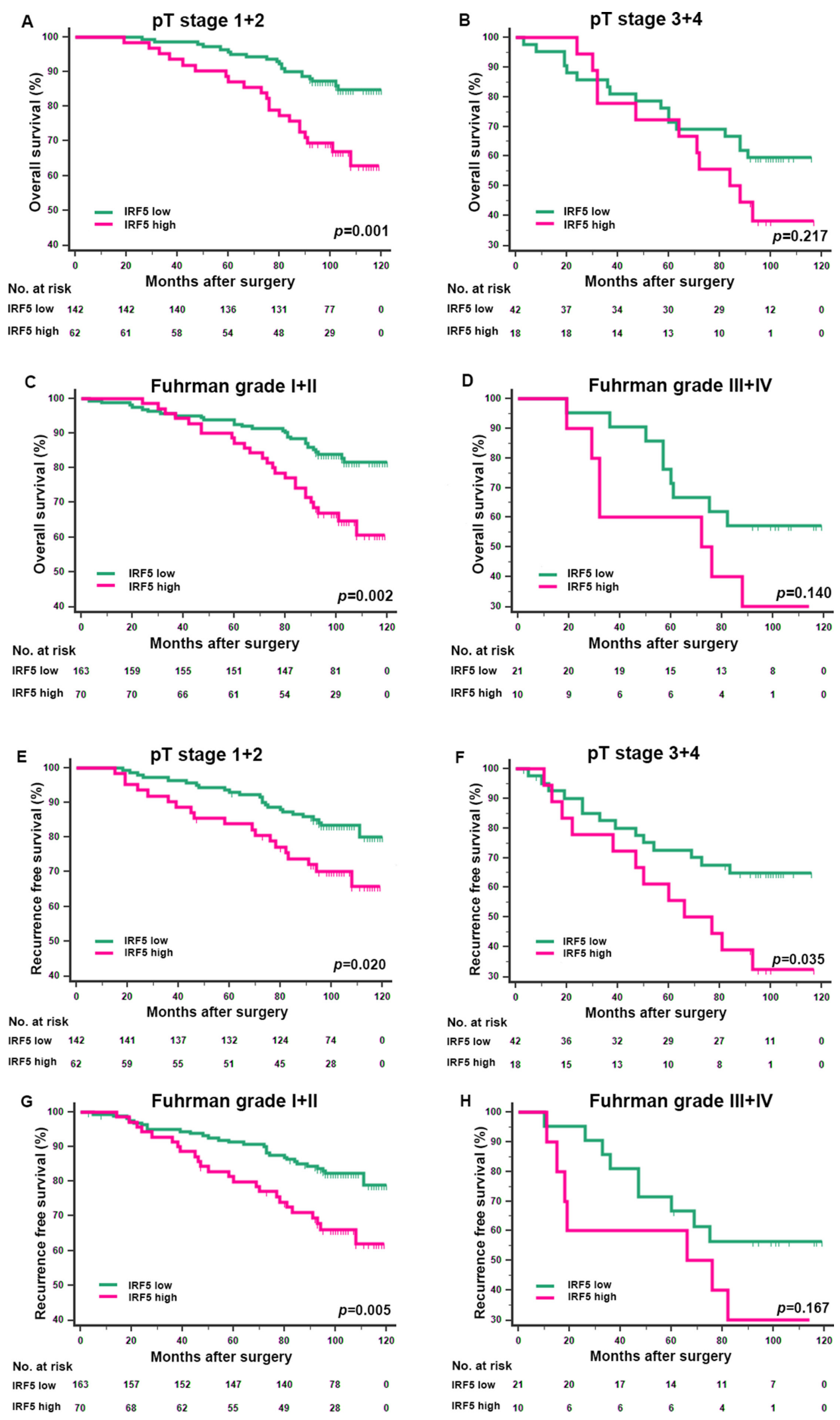

Figure 3: Kaplan-Meier analyses for overall survival and recurrence free survival of patients in pT stage and Fuhrman grade subgroups. Overall survival for patients in the pT stage (1+2) group (A) pT (3+4) stage group (B) Fuhrman grade (I+II) group (C) and Fuhrman grade (III+IV) group (D) according to IRF5 expression; recurrence free survival for patients in the pT stage (1+2) group (E) pT stage (3+4) group (F) Fuhrman grade (I+II) group (G) and Fuhrman grade (III+IV) group (H) according to IRF5 expression; $p$-value was calculated by Log rank test, $p<0.05$ was regarded as statistically significant. 
Increasing studies support the notion that inflammation and cancer immune responsiveness may share a common determinism [25]. IRF5 proved to be associated with some autoimmune diseases like systemic lupus erythematosus $[26,27]$ and rheumatoid arthritis [28].

In fact, the role of IRF5 in tumor genesis remains controversial. As IRF5 can induce p21, Bak, Bax, and Caspase 8, making it a potential candidate of tumorsuppressor [29-31]. In immortalized tumor cell lines and primary samples from patients with hematological malignancies, IRF5 expression is always absent or significantly decreased [13]. It is reported that in hepatocellular carcinoma and gastric cancer, IRF5 expression is down-regulated due to gene promoter hyper-methylation $[32,33]$. However, Michele et al. showed that in thyroid cancers cells, IRF5 displays tumor-promoting property
[34]. And in the present results, we also defined IRF5 as an independent risk factor for ccRCC progression.

Accumulating evidence has unveiled robust and supportive contributions of tumor microenvironment (TME) to the survival, self-renewal and tumorigenic activities of tumors $[35,36]$. However how the functional and phenotypic heterogeneity of tumor itself, in turn, impacts the pathophysiological activities of TEM remains unknown. IRF5 mediates induction of multiple proinflammatory cytokines, such as IL-1, IL-6, and TNF-a [16] and these cytokines had proved to be indication of a worse outcome in quite a few tumors [37-39]. In addition, Masahisa et al. found that resistance to cytotoxic chemotherapy renders cancer stem cells (CSCs) ability to create immunosuppressive microenvironments through IRF5 pathways [40]. Tumor associated macrophages (TAMs) are

\section{A Nomogram for overall survival}

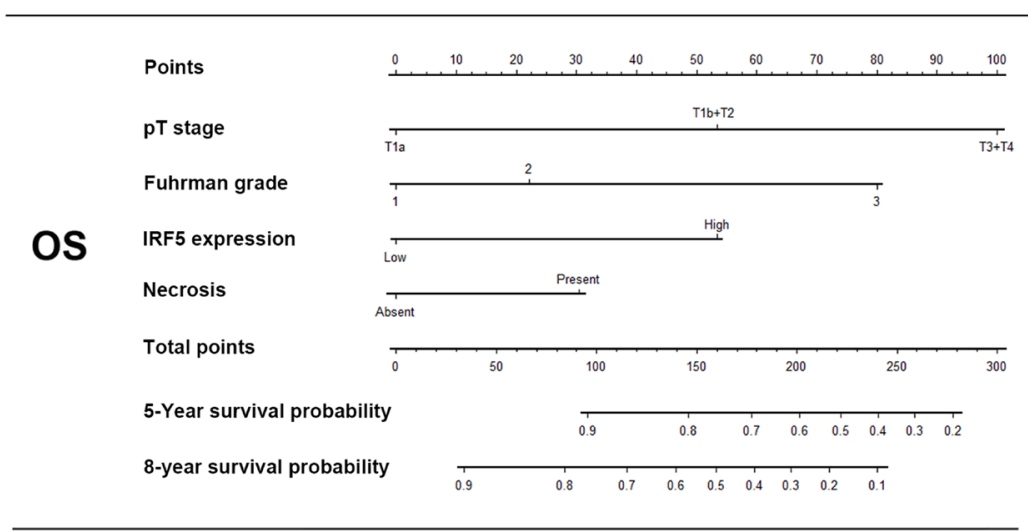

B Nomogram for recurrence free survival

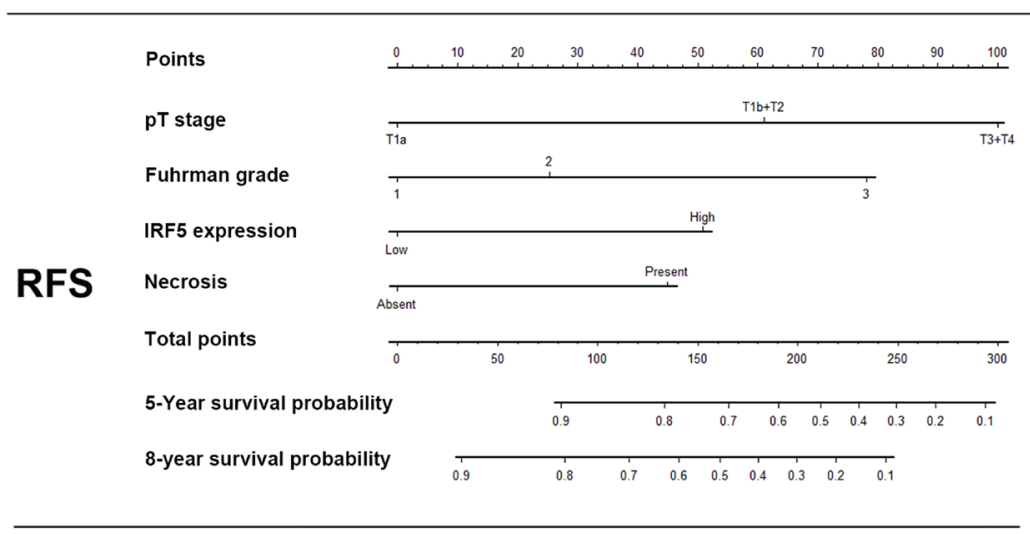

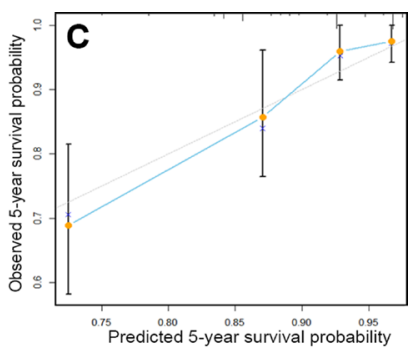
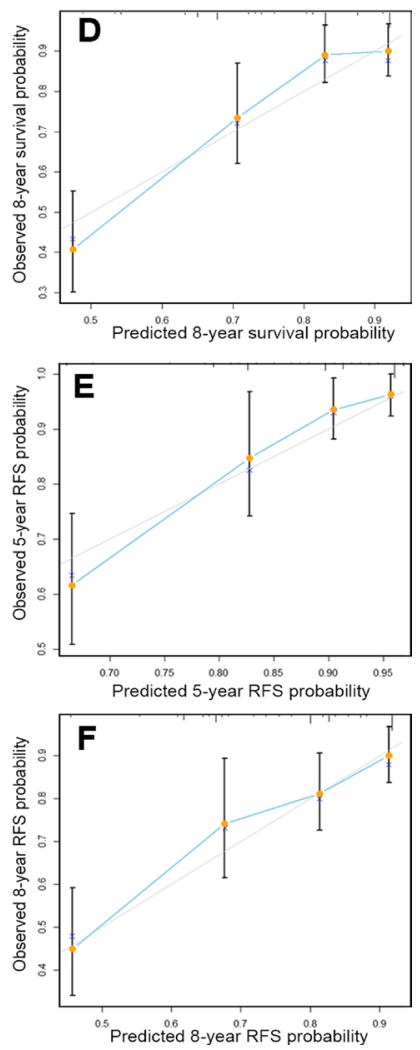

Figure 4: Nomogram for predicting 5- and 8-year overall survival and recurrence free survival in patients with ccRCC. Nomogram for predicting 5- and 8- year OS (A) Nomogram for predicting 5- and 8- year RFS (B) Calibration plot for nomogram predicted and observed 5-year overall survival rate $(\mathbf{C})$ and 8-year overall survival rate (D) Calibration plot for nomogram predicted and observed 5 -year recurrence free survival rate $(\mathbf{E})$ and 8-year recurrence free survival rate $(\mathbf{F})$ higher total point indicated a more adverse outcome probability; Line of dashes: ideal model, vertical bars: $95 \%$ confident interval. 
one of the major populations of tumor infiltrating immune cells and have been shown to play critical roles in promoting the tumorigenic activities [41-43]. And in our previous study, we found polarized TAMs were novel independent prognosticator in patients with ccRCC [44]. Constitutive activation of IRF5 has been identified as indispensable for triggering M-CSF production and the resultant monocyte infiltration and differentiation of M2-type macrophages in tumor tissues [40]. RCC monocytes express a mixture of both M1 and M2 gene, and pro-inflammatory monocytes in RCC display a tumor-promoting phenotype [45], which means the inflammatory microenvironment may be a hallmark of ccRCC. Recently, our knowledge of IRF5 in ccRCC remains limited and the mechanism responsible for carcinogenesis is still lacking and merits further research.

In conclusion, we have revealed that IRF5 expression could serve as an adverse independent prognostic factor in non-metastatic ccRCC. Higher IRF5 expression indicated worse clinical outcomes than the counterparts. Moreover, the prediction model we built in the present study could further stratify the patients with different outcomes. Above all, we have reason to believe that IRF5 might promote ccRCC progression. Limitations of the present study are the retrospective design and only non-metastatic disease are involved. A multicenter and prospective study is needed to validate the results.

\section{MATERIALS AND METHODS}

\section{Patient selection}

Medical records of patients who were treated in Zhongshan Hospital, Fudan University (Shanghai, China) between Jan 2005 and Jun 2007 were reviewed. We retrospectively recruited 264 patients who underwent radical nephrectomy or nephron-sparing surgery at Zhongshan Hopital. Following clinicopathological characters include age, sex, tumor size, TNM stage, pathological data and ECOG PS were collected from the database of the institution. The corresponding department approved the access to medical records. Tumor stage and postoperative histopathological type were determined according to the 2010 AJCC TNM classification [46]. The inclusion criteria were as follows: (1) the histopathological type should be clear cell RCC, (2) no history of neoadjuvant therapy before surgery, (3) no history of other malignancy before, (4) patients with lymph node or distant metastasis were excluded from the present study. We invited a practiced pathologist to re-evaluated all sections from nephrectomy samples to verify the Fuhrman grades, histology type, and presence of necrosis. We also excluded the patient whose corresponding tissue was mostly necrosis $(>80 \%)$ or histopathology features represented a combination of clear cell RCC and other RCC type. Patients were followed up every 6 months or earlier for the first 2 years right after the nephrectomy and every 12 months thereafter. The study was approved Clinical Research Ethics Committee of Zhongshan Hospital, Fudan University with the approval number B2015-030 in Feb 2015. Written, informed consent was obtained from each individual enrolled in the study.

\section{Immunohistochemistry and evaluation}

We performed immunohistochemistry staining on tissue microarrays (TMAs). The TMAs construction was described previously[47]. We used anti-IRF5 antibody (ab181553, Abcam, Cambridge, MA, USA) as the primary antibody in the procedure. Two independent pathologists who were blind to the clinical outcome, were asked to evaluate the staining intensity and extent. The intensity score was graded as 0 (negative), 1 (weak), 2 (moderate), and 3 (strong); the extent score was calculated by the percentage of the positive cells $(0 \%-100 \%)$. We multiplied the staining intensity and extent to calculate the expression score ranging from 0 to 300 . X-Tile software (Yale University School of Medicine, New Haven, CT, USA) was used to determine the cutoff point of high/low expression through minimum $p$ value method based on patients' OS information, and 180 was selected as the cutoff point.

\section{Statistical analyses}

We assessed correlations between IRF5 expression and patient clinical characteristics with $t$ test, $\chi^{2}$ test or Fisher's exact test. Kaplan-Meier survival curves were established and statistical significance was analyzed by log-rank test. Cox proportional hazard models were used to analyze the effect of patient characteristics, clinical features and IRF5 expression on OS and RFS. All the statistical tests were two sided and $p<0.05$ was considered statistical significant. We generated two nomogram models using R software with "rms" package (R Foundation for Statistical Computing, Vienna, Austria). Parameters with $p<0.1$ level in multivariate analyses were included in nomogram. Calibration plots for OS and RFS were constructed to exhibit the performance of the present model. Harrell's concordance indices (c-indices) were calculated to test the prognostic accuracy. All statistical analyses above were performed using SPSS version 19.0 (SPSS Inc., IL, Chicago, USA) and R software with "rms" package (R Foundation for Statistical Computing, Vienna, Austria).

\section{Authors' contributions}

Q. Bai for acquisition of data, analysis and interpretation of data, statistical analysis and drafting of the manuscript; L. Liu, Y. Xia, J. Wang, W. Xi, Y. Qu, Y. Xiong and Q. Long for technical and material support; 
J. Xu and J. Guo for study concept and design, analysis and interpretation of data, drafting of the manuscript, obtained funding and study supervision. All authors read and approved the final manuscript.

\section{ACKNOWLEDGMENTS}

This study was funded by grants from National Basic Research Program of China (2012CB822104), National Key Projects for Infectious Diseases of China (2012ZX10002012-007, 2016ZX10002018-008), National Natural Science Foundation of China (31100629, 31270863, $81372755,31470794,81401988,81402082$, 81402085, $81471621,81472227,81472376,31570803,81501999$ and 81572352) and Program for New Century Excellent Talents in University (NCET-13-0146). All these study sponsors have no roles in the study design, in the collection, analysis, and interpretation of data.

\section{CONFLICTS OF INTEREST}

The authors declare no conflicts of interest.

\section{REFERENCES}

1. Siegel RL, Miller KD, Jemal A. Cancer Statistics, 2017. CA Cancer J Clin. 2017; 67:7-30.

2. Escudier B, Porta C, Schmidinger M, Algaba F, Patard JJ, Khoo V, Eisen T, Horwich A, Group EGW. Renal cell carcinoma: ESMO Clinical Practice Guidelines for diagnosis, treatment and follow-up. Ann Oncol. 2014; 25:iii49-56.

3. Hollingsworth JM, Miller DC, Daignault S, Hollenbeck BK. Five-year survival after surgical treatment for kidney cancer: a population-based competing risk analysis. Cancer. 2007; 109:1763-1768.

4. Chow WH, Devesa SS. Contemporary epidemiology of renal cell cancer. Cancer J. 2008; 14:288-301.

5. Stewart GD, O'Mahony FC, Powles T, Riddick AC, Harrison DJ, Faratian D. What can molecular pathology contribute to the management of renal cell carcinoma? Nat Rev Urol. 2011; 8:255-265.

6. Mickisch GH, Garin A, van Poppel H, de Prijck L, Sylvester R, European Organisation for R, Treatment of Cancer Genitourinary G. Radical nephrectomy plus interferon-alfa-based immunotherapy compared with interferon alfa alone in metastatic renal-cell carcinoma: a randomised trial. Lancet. 2001; 358:966-970.

7. Flanigan RC, Salmon SE, Blumenstein BA, Bearman SI, Roy V, McGrath PC, Caton JR Jr, Munshi N, Crawford ED. Nephrectomy followed by interferon alfa- $2 \mathrm{~b}$ compared with interferon alfa- $2 \mathrm{~b}$ alone for metastatic renal-cell cancer. N Engl J Med. 2001; 345:1655-1659.

8. Flanigan RC, Mickisch G, Sylvester R, Tangen C, Van Poppel H, Crawford ED. Cytoreductive nephrectomy in patients with metastatic renal cancer: a combined analysis. J Urol. 2004; 171:1071-1076.

9. Barnes BJ, Moore PA, Pitha PM. Virus-specific activation of a novel interferon regulatory factor, IRF-5, results in the induction of distinct interferon alpha genes. J Biol Chem. 2001; 276:23382-23390.

10. Barnes BJ, Kellum MJ, Field AE, Pitha PM. Multiple regulatory domains of IRF-5 control activation, cellular localization, and induction of chemokines that mediate recruitment of $\mathrm{T}$ lymphocytes. Mol Cell Biol. 2002; 22:5721-5740.

11. Saliba DG, Heger A, Eames HL, Oikonomopoulos S, Teixeira A, Blazek K, Androulidaki A, Wong D, Goh FG, Weiss M, Byrne A, Pasparakis M, Ragoussis J, et al. IRF5:RelA interaction targets inflammatory genes in macrophages. Cell Rep. 2014; 8:1308-1317.

12. Lien C, Fang CM, Huso D, Livak F, Lu R, Pitha PM. Critical role of IRF-5 in regulation of B-cell differentiation. Proc Natl Acad Sci USA. 2010; 107:4664-4668.

13. Barnes BJ, Kellum MJ, Pinder KE, Frisancho JA, Pitha PM. Interferon regulatory factor 5 , a novel mediator of cell cycle arrest and cell death. Cancer research. 2003; 63:6424-6431.

14. Hu G, Barnes BJ. IRF-5 is a mediator of the death receptorinduced apoptotic signaling pathway. J Biol Chem. 2009; 284:2767-2777.

15. Yanai $\mathrm{H}$, Chen $\mathrm{HM}$, Inuzuka $\mathrm{T}$, Kondo $\mathrm{S}$, Mak TW, Takaoka A, Honda K, Taniguchi T. Role of IFN regulatory factor 5 transcription factor in antiviral immunity and tumor suppression. Proc Natl Acad Sci USA. 2007; 104:3402-3407.

16. Krausgruber $\mathrm{T}$, Blazek $\mathrm{K}$, Smallie $\mathrm{T}$, Alzabin $\mathrm{S}$, Lockstone H, Sahgal N, Hussell T, Feldmann M, Udalova IA. IRF5 promotes inflammatory macrophage polarization and TH1-TH17 responses. Nat Immunol. 2011; 12:231-238.

17. Takaoka A, Yanai H, Kondo S, Duncan G, Negishi H, Mizutani T, Kano S, Honda K, Ohba Y, Mak TW, Taniguchi T. Integral role of IRF-5 in the gene induction programme activated by Toll-like receptors. Nature. 2005; 434:243-249.

18. Rini B, Goddard A, Knezevic D, Maddala T, Zhou M, Aydin H, Campbell S, Elson P, Koscielny S, Lopatin M, Svedman C, Martini JF, Williams JA, et al. A 16-gene assay to predict recurrence after surgery in localised renal cell carcinoma: development and validation studies. Lancet Oncol. 2015; 16:676-685.

19. Schutz FA, Pomerantz MM, Gray KP, Atkins MB, Rosenberg JE, Hirsch MS, McDermott DF, Lampron ME, Lee GS, Signoretti S, Kantoff PW, Freedman ML, Choueiri TK. Single nucleotide polymorphisms and risk of recurrence of renal-cell carcinoma: a cohort study. Lancet Oncol. 2013; 14:81-87.

20. Leibovich BC, Han KR, Bui MH, Pantuck AJ, Dorey FJ, Figlin RA, Belldegrun A. Scoring algorithm to predict survival after nephrectomy and immunotherapy in patients with metastatic renal cell carcinoma: a stratification tool for prospective clinical trials. Cancer. 2003; 98:2566-2575. 
21. Kattan MW, Reuter V, Motzer RJ, Katz J, Russo P. A postoperative prognostic nomogram for renal cell carcinoma. J Urol. 2001; 166:63-67.

22. Hoffmann NE, Sheinin Y, Lohse CM, Parker AS, Leibovich BC, Jiang Z, Kwon ED. External validation of IMP3 expression as an independent prognostic marker for metastatic progression and death for patients with clear cell renal cell carcinoma. Cancer. 2008; 112:1471-1479.

23. Nicolini A, Carpi A, Rossi G. Cytokines in breast cancer. Cytokine \& growth factor reviews. 2006; 17:325-337.

24. Barnes BJ, Richards J, Mancl M, Hanash S, Beretta L, Pitha PM. Global and distinct targets of IRF-5 and IRF7 during innate response to viral infection. J Biol Chem. 2004; 279:45194-45207.

25. Grivennikov SI, Greten FR, Karin M. Immunity, inflammation, and cancer. Cell. 2010; 140:883-899.

26. Demirci FY, Manzi S, Ramsey-Goldman R, Minster RL, Kenney M, Shaw PS, Dunlop-Thomas CM, Kao AH, Rhew E, Bontempo F, Kammerer C, Kamboh MI. Association of a common interferon regulatory factor 5 (IRF5) variant with increased risk of systemic lupus erythematosus (SLE). Ann Hum Genet. 2007; 71:308-311.

27. Graham RR, Kozyrev SV, Baechler EC, Reddy MV, Plenge RM, Bauer JW, Ortmann WA, Koeuth T, Gonzalez Escribano MF, Argentine Spanish Collaborative G, PonsEstel B, Petri M, et al. A common haplotype of interferon regulatory factor 5 (IRF5) regulates splicing and expression and is associated with increased risk of systemic lupus erythematosus. Nat Genet. 2006; 38:550-555.

28. Dawidowicz K, Allanore Y, Guedj M, Pierlot C, Bombardieri S, Balsa A, Westhovens R, Barrera P, Alves H, Teixeira VH, Petit-Teixeira E, van de Putte L, van Riel P, et al. The interferon regulatory factor 5 gene confers susceptibility to rheumatoid arthritis and influences its erosive phenotype. Ann Rheum Dis. 2011; 70:117-121.

29. Mori T, Anazawa Y, Iiizumi M, Fukuda S, Nakamura Y, Arakawa $\mathrm{H}$. Identification of the interferon regulatory factor 5 gene (IRF-5) as a direct target for p53. Oncogene. 2002; 21:2914-2918.

30. Barnes BJ, Field AE, Pitha-Rowe PM. Virus-induced heterodimer formation between IRF-5 and IRF-7 modulates assembly of the IFNA enhanceosome in vivo and transcriptional activity of IFNA genes. J Biol Chem. 2003; 278:16630-16641.

31. Fagin JA. Minireview: branded from the start-distinct oncogenic initiating events may determine tumor fate in the thyroid. Mol Endocrinol. 2002; 16:903-911.

32. Shin SH, Kim BH, Jang JJ, Suh KS, Kang GH. Identification of novel methylation markers in hepatocellular carcinoma using a methylation array. J Korean Med Sci. 2010; 25:1152-1159.

33. Yamashita $M$, Toyota $M$, Suzuki $H$, Nojima $M$, Yamamoto E, Kamimae S, Watanabe Y, Kai M, Akashi H, Maruyama R, Sasaki Y, Yamano H, Sugai T, et al. DNA methylation of interferon regulatory factors in gastric cancer and noncancerous gastric mucosae. Cancer Sci. 2010; 101:1708-1716.

34. Massimino M, Vigneri P, Fallica M, Fidilio A, Aloisi A, Frasca F, Manzella L. IRF5 promotes the proliferation of human thyroid cancer cells. Mol Cancer. 2012; 11:21.

35. Quail DF, Joyce JA. Microenvironmental regulation of tumor progression and metastasis. Nat Med. 2013; 19: 1423-1437.

36. Gajewski TF, Schreiber H, Fu YX. Innate and adaptive immune cells in the tumor microenvironment. Nat Immunol. 2013; 14:1014-1022.

37. Xu L, Zhu Y, An H, Liu Y, Lin Z, Wang G, Xu J. Clinical significance of tumor-derived IL-1beta and IL-18 in localized renal cell carcinoma: Associations with recurrence and survival. Urol Oncol. 2015; 33:68 e69-16.

38. Fu Q, Chang Y, An H, Fu H, Zhu Y, Xu L, Zhang W, Xu J. Prognostic value of interleukin-6 and interleukin-6 receptor in organ-confined clear-cell renal cell carcinoma: a 5-year conditional cancer-specific survival analysis. Br J Cancer. 2015; 113:1581-1589.

39. Smith MP, Sanchez-Laorden B, O'Brien K, Brunton H, Ferguson J, Young H, Dhomen N, Flaherty KT, Frederick DT, Cooper ZA, Wargo JA, Marais R, Wellbrock C. The immune microenvironment confers resistance to MAPK pathway inhibitors through macrophage-derived TNFalpha. Cancer Discov. 2014; 4:1214-1229.

40. Jinushi M. Role of cancer stem cell-associated inflammation in creating pro-inflammatory tumorigenic microenvironments. Oncoimmunology. 2014; 3:e28862.

41. Lewis CE, Pollard JW. Distinct role of macrophages in different tumor microenvironments. Cancer Res. 2006; 66:605-612.

42. De Palma M, Lewis CE. Macrophage regulation of tumor responses to anticancer therapies. Cancer cell. 2013; 23:277-286.

43. Ruffell B, Coussens LM. Macrophages and therapeutic resistance in cancer. Cancer cell. 2015; 27:462-472.

44. Xu L, Zhu Y, Chen L, An H, Zhang W, Wang G, Lin Z, $\mathrm{Xu}$ J. Prognostic value of diametrically polarized tumorassociated macrophages in renal cell carcinoma. Ann Surg Oncol. 2014; 21:3142-3150.

45. Chittezhath M, Dhillon MK, Lim JY, Laoui D, Shalova IN, Teo YL, Chen J, Kamaraj R, Raman L, Lum J, Thamboo TP, Chiong E, Zolezzi F, et al. Molecular profiling reveals a tumor-promoting phenotype of monocytes and macrophages in human cancer progression. Immunity. 2014; 41:815-829.

46. Edge SB, Compton CC. The American Joint Committee on Cancer: the 7th edition of the AJCC cancer staging manual and the future of TNM. Ann Surg Oncol. 2010; 17: 1471-1474.

47. Bai Q, Liu L, Xia Y, Long Q, Wang J, Xu J, Guo J. Prognostic significance of ST3GAL-1 expression in patients with clear cell renal cell carcinoma. BMC Cancer. 2015; 15:880. 